\title{
SISTEMAS DE BIBLIOTECAS: UMA ANÁLISE A PARTIR DE SEUS REGIMENTOS
}

\author{
LIBRARY SYSTEMS: \\ AN ANALYSIS FROM REGIMENTS \\ SISTEMAS DE BIBLIOTECA: \\ UN ANÁLISIS DE LOS REGIMIENTOS
}

${ }^{1}$ Marouva Fallgatter Faqueti, ${ }^{1}$ Sigrid Weiss Dutra, ${ }^{1}$ João Bosco da Mota Alves, ${ }^{1}$ Aires José Rover

${ }^{1}$ Universidade Federal de Santa Catarina

\section{Correspondência}

${ }^{1}$ Marouva Fallgatter Faqueti

Universidade Federal de Santa Catarina

Floriamópolis, SC

Email: marouva.faqueti@gmail.com

ORCID: http://orcid.org/0000-0002-8935-

$\underline{8601}$

Submetido em: 27-07-2016

Aceito em: 23-05-2017

Publicado: 07-06-2017

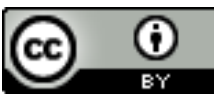

JITA: DD. Academic libraries. 
RESUMO: Bibliotecas de Instituições de Ensino Superior (IES), em sua grande maioria, estão organizadas estruturalmente como "Sistema de Bibliotecas" (SIBIs). Neste artigo apresenta-se reflexões sobre a visão sistêmica de SIBIs sustentando-se nos referenciais teóricos de Bertalanffy e de Maturana e Varela. Com o objetivo de analisar as semelhanças e diferenças entre estruturas organizacionais de SIBIs, dentro de uma abordagem qualitativa, realizou-se uma pesquisa documental composta de 15 regimentos de SIBIs (disponíveis na $w e b$ ) pertencentes a instituições de ensino que oferecem cursos de nível superior, abrangendo universidades federais, estaduais e institutos federais. Para tanto, utilizou-se os seguintes critérios de seleção: a) 33\% de regimentos com data de aprovação anterior a 2000; b) 33\% com aprovação entre 2001 e 2010; c) $33 \%$ com aprovação entre 2011 e 2016. Os resultados apontam que os sistemas mantêm uma organização estrutural verticalizada, porém, existem indicativos de uma tendência a estruturações em SIBIs com menor centralização de serviços e de poder decisório. Por fim, recomenda-se novos estudos que aprofundem a discussão, pois é mister que se busque o repensar de novas estruturas organizacionais que facilitem o desenvolvimento de uma gestão mais inovadora e criativa.

PALAVRAS-ChaVE: Biblioteca universitária. Sistema. Administração de biblioteca.

ABSTRACT: Most of the Libraries of Higher Education Institutions are structurally organized as "Library Systems". This article presents reflections on systemic vision of "Library Systems", based on the theoretical support frames of Bertalanffy, Maturana and Varela. In order to analyze the similarities and differences between organizational structures "Library Systems" within a qualitative approach, there was a documentary research composed of 15 regiments SIBIs (available online) belonging to educational institutions offering higher education courses, including universities federal, state and federal institutes. Therefore, the following criteria were used: a) 33\% regiments approved before 2000; b) 33\% approved between 2001 and 2010; c) 33\% approved between 2011 and 2016. The results show that the systems maintain a vertical organizational structure; however, there is evidence of a tendency to restructurings in SIBIs with less centralization of services and decision-making power. Finally, it is recommended further studies to deepen the debate, it is necessary to seek new organizational structures or rethink it in order to facilitate the development of a more innovative and creative management.

KEYWORDS: Academic library. System. Library administration.

RESUMEN: La mayoría de las Bibliotecas de Instituciones de Educación Superior (IES) se organizan estructuralmente como "Sistema de Bibliotecas" (SIBIs). Este artículo presenta reflexiones sobre la visión sistémica del SIBIs, apoyándose sostener en los marcos teóricos de Bertalanffy, Maturana y Varela. Con el fin de analizar las similitudes y diferencias entre las estructuras organizativas del SIBIs dentro de un enfoque cualitativo, hubo una investigación documental compuesto por 15 regimientos SIBIs (disponible en la web) que pertenecen a instituciones educativas que ofrecen cursos de educación superior, incluyendo universidades federales, estatales e institutos federales. Por lo tanto, se utilizaron los siguientes criterios de selección: a) 33\% regimientos con fecha de aprobación antes del 2000; b) 33\% con aprobación entre 2001 y 2010; c) 33\% con aprobación entre 2011 y 2016. Los resultados muestran que los sistemas mantienen una estructura organizativa vertical, sin embargo, hay indicios de una tendencia a estructuraciones en SIBIs con menor centralización de los servicios y el poder de toma de decisiones. Por último, se recomienda realizar nuevos estudios para profundizar el debate, pues es necesario que se busquen o se replanteen nuevas estructuras organizativas para facilitar el desarrollo de una gestión más innovadora y creativa.

PALABRAS CLAVE: Biblioteca universitaria. Sistema. Administración de biblioteca

\begin{tabular}{l|l|l} 
v.15 & n.3 \\
\hline
\end{tabular}

p.715-735

set./dez. 2017 


\section{INTRODUÇÃ̃o}

A forma como uma organização se estrutura revela traços sob quais princípios ela está alicerçada. Instituições de ensino que oferecem cursos de nível superior, como universidades, faculdades e instituições da Rede Federal de Educação Profissional Científica e Tecnológica (RFEPCT), possuem uma ou mais bibliotecas em sua estrutura. Suas funções primordiais abarcam a promoção do acesso e uso de informações registradas bem como a produção de novos conhecimentos, atendendo às necessidades institucionais de ensino, pesquisa, extensão, administração e inovação. Para que as bibliotecas de cada instituição possam alcançar seus propósitos com a qualidade desejada, torna-se relevante que busquem se organizar por meio de estruturas que possibilitem o desenvolvimento de seus trabalhos de forma integrada.

A complexidade do universo da gestão administrativa de Bibliotecas, sejam elas classificadas como bibliotecas públicas, universitárias, especializadas ou comunitárias etc., pode ser compreendida sob a perspectiva sistêmica. Na literatura nacional, os primeiros escritos encontrados que fomentam a reflexão sobre a importância da realização de ações integrativas e cooperativas foram escritos por Hamar (1967).

Nessa época, as condições macro ambiental impactaram sobre as bibliotecas de forma mais incisiva. Influências políticas educacionais de reestruturação das universidades brasileiras (BRASIL, 1968) favoreceram para que as bibliotecas se fortalecessem institucionalmente e passassem a vislumbrar novos marcos de estruturação organizacional que viabilizassem a integração das bibliotecas de cada instituição.

Diferentes estruturas organizacionais foram idealizadas e implementadas ao longo das últimas cinco décadas tendo como suporte teórico a visão sistêmica. Estudos como os de Ferreira (1980) e Mercadante (1990) são referências importantes desse movimento de concepção de "Sistemas de Bibliotecas" em universidades, assim como o trabalho de Becker e Faqueti (2016), que mapeia os tipos de estrutura organizacional em bibliotecas da RFEPCT.

Considerando a caminhada experienciada pelas bibliotecas de universidades federais, estaduais e da RFEPCT pergunta-se: a) as estruturas organizacionais de SIBIs vêm sofrendo mudanças ao longo das décadas? b) quais são as similaridades e diferenças entre os Sistemas existentes?

Embasados nessas questões, objetivou-se, neste estudo descritivo qualitativo em bases documentais, analisar as estruturas de SIBIs pertencentes a instituições de ensino que oferecem cursos de nível superior no Brasil. A partir de seus regimentos, foi possível identificar similaridades e diferenças entre os modelos de SIBIs implantados e mapear alterações ocorridas ao longo das décadas. 


\section{VISÃO SISTÊMICA}

A visão sistêmica emergiu no século $\mathrm{XX}$, dentro de um contexto em que a ciência apontava descobertas em diversas áreas do conhecimento, que desestabilizavam as teorias vigentes. Dentre elas pode-se citar os avanços na área da Física, como, por exemplo, a Teoria da Relatividade de Einsten. Marcava-se, assim, o início de um novo paradigma, em que a era das certezas e do pensamento linear abre espaço para uma compreensão do universo a partir do incerto, com múltiplas probabilidades e possibilidades.

Nesse sentido, o biólogo Ludwig von Bertalanffy (c1969) foi o primeiro estudioso a formalizar uma teoria, na década de 1950, denominada "Teoria Geral dos Sistemas" (TGS). Ao conceber essa teoria, construída a partir de seus estudos relacionados à Biologia, o autor reagia contra o reducionismo presente no enfoque mecanicista dos estudos científicos e tentava resgatar a unidade da ciência. Segundo Alves (2012, p. 162):

A Teoria Geral de Sistemas é a ciência da inteireza, da totalidade. Estuda o sistema, seu ambiente, suas respectivas estruturas, a fronteira que o separa do ambiente e, finalmente o acoplamento estrutural sistema-ambiente, independentemente da área de conhecimento envolvida. É o que se convencionou chamar de Visão Sistêmica.

Para compreender os princípios da visão sistêmica, faz-se necessário adentrar na conceituação de Sistema. Alves (2012, p.96), estudioso dos preceitos de Bertalanffy, utiliza a definição seguinte: "Um sistema é uma construção mental de uma organização contendo uma coleção de objetos inter-relacionados em uma dada estrutura, perfazendo um todo (uma unidade) com alguma funcionalidade, que o identifica como tal." Segundo o autor, essa definição enquadra-se em uma perspectiva fraca, ou seja, pode contemplar um maior número de objetos.

Esse tipo de definição mais aberta é recomendada em contextos interdisciplinares. Sua leitura permite identificar os três elementos que compõem um sistema: uma organização, um conjunto de objetos (componentes) e uma estrutura. Maturana, (2001), a partir de seus estudos sobre a "Biologia do Conhecer", também dentro do campo da Biologia, entende que Organização se refere às relações que acontecem entre os componentes, e Estrutura é o conjunto formado pelos componentes e suas relações. Para ele, um sistema é determinado por sua estrutura, e esta sofre mudanças por meio de suas interações com o ambiente, porém, o que determina a criação ou a morte de um sistema é a sua organização:

A organização é necessariamente uma invariante. Se a organização define a identidade de classe de uma unidade composta ou de um sistema, no momento em que mudar a organização, muda a identidade de classe - o sistema passa a ser outra coisa. [...] Se alguém corta esta mesa pela metade, diz: "Já não tenho mesa." O que é que se perdeu? A organização. De modo que a organização se perde se houver mudanças estruturais nas quais ela não se conserva. (MATURANA, 2001, p. 77) 
Um Sistema sempre é uma abstração de um observador, uma construção mental, que, diante de uma dada realidade contextual, consegue focar sobre um objeto e vislumbrá-lo como um sistema.

Para obter maior clareza sobre o conceito de sistemas, utiliza-se o livro como metáfora representativa de um sistema. Sendo assim, inicia-se com uma definição disponível no Dicionário Houaiss, em que o livro é uma "coleção de folhas de papel, impressas ou não, cortadas, dobradas e reunidas em cadernos cujos dorsos são unidos por meio de cola, costura, etc., formando um volume que se recobre com capa resistente" (HOUAISS; VILLAR; FRANCO, 2009, p.1190). Pode-se, assim, observar que livros possuem alguns elementos estruturais como papel, cola ou costura, uma capa etc., mas esses elementos por si só não caracterizam o livro. É preciso que eles estejam organizados de uma forma específica, para que possam se transformar em livro.

Voltando ao conceito de sistema, verifica-se que todo sistema tem uma funcionalidade. Qual seria a funcionalidade de um livro? Sua função maior é atuar como suporte para registro de dados e informações. Esta é a sua finalidade base. Os conteúdos informacionais nele registrados se destinam às mais distintas finalidades, mas todos contêm dados e informações.

Na história do livro, pode-se verificar que sua estrutura vem se alterando conforme o meio se altera, e aqui se pode compreender mais um dos princípios do sistema - sua capacidade de conservação e adaptação ao meio. O conceito de Acoplamento Estrutural, criado por Maturana (2001), expõe claramente a interdependência de um sistema com seu meio: "Chamo esta dinâmica histórica de mudanças estruturais coerentes do organismo e do meio, bem como sua condição de congruência dinâmica estrutural, de acoplamento Estrutural" (MATURANA, 2001, p. 185). Ou seja, trata-se da adaptação de um sistema ao seu meio. O meio produz perturbações que podem impulsionar mudanças internas a um sistema. Apesar de se ter sido criado a partir de estudos da Biologia, o conceito se aplica a diferentes áreas do conhecimento, como nas ciências sociais.

Portanto, o livro, ora entendido como um sistema, interfere no meio e sofre interferência deste. Sua história está imbricada com os avanços tecnológicos. À medida que novas tecnologias surgem e possibilitam formas de registro da informação diferenciadas, o livro sofre igualmente modificações na sua estrutura. Inicialmente, os escritos eram gravados em tábuas de argila, madeira, dentre outros. Depois surgiu o papiro (que originou o termo Papel). Com o surgimento do papel criado pelo chineses e, mais tarde, com o advento da imprensa no século XVI, o livro ganhou força e seu uso se expandiu exponencialmente na sociedade. No século XX, outra grande inovação aconteceu, e que possibilitou o surgimento do livro na versão digital. 
Apesar de todas essas adaptações que o livro sofreu, em função de perturbações no ambiente (avanços tecnológicos), ele sobreviveu ao longo de todos esses anos. Sua estrutura mudou, porém, a organização-fim para a qual foi criado permaneceu.

Essa explicação sobre o funcionamento de um sistema utilizando o livro como metáfora reuniu conceitos de Bertalanffy (c1969) e de Maturana e Varela (2001), porém, é necessário esclarecer que existe uma diferença marcante, e que não pode ser identificada na história do livro, que é a noção de sistema como uma organização aberta e fechada.

Para Bertalanffy (c1969), o sistema é uma unidade estruturada aberta e permeável a influências externas. Isso significa que ele interage com o meio ambiente que o circunda, com o qual troca informações e, dessa forma, evita a entropia.

Já para Maturana e Varela (2001), os sistemas são fechados, pois, segundo seus estudos com seres vivos, os autores comprovam que os processos de autorrenovação ocorrem dentro do sistema. Isto não significa dizer que não ele não sofre perturbações externas, e sim que a responsabilidade pela mudança se processa no seu interior:

Sistemas vivos são sistemas autopoiéticos moleculares. Enquanto sistemas moleculares, os sistemas vivos são abertos ao fluxo de matéria e energia. Enquanto sistemas autopoiéticos, sistemas vivos são sistemas fechados em sua dinâmica de estados, no sentido de que eles são vivos apenas enquanto todas as suas mudanças estruturais forem mudanças estruturais que conservam sua autopoiese. Ou seja, um sistema vivo morre quando sua autopoiese para de ser conservada através de suas mudanças estruturais. (MATURANA, 2001, p. 175).

A citação acima demonstra que Maturana e Varela não negam a existência de fluxos de energia e matéria entre o ser vivo e o ambiente, mas o que os autores destacam é o fato de que o processo de mudança ocorre dentro do sistema e não de fora para dentro. As perturbações ambientais contingenciam o processo das mudanças internas.

A visão de sistema autopoiético foi absorvida por Luhmann (1998) em seus estudos sobre organizações sociais.

Morin (2006, p. 87) corrobora também essa noção autopoiética aplicada às organizações complexas, quando afirma que "Como organismo vivo, a empresa se autoorganiza e faz a sua autoprodução. Ao mesmo tempo, ela faz a auto-eco-organização e a autoeco-produção".

\section{BIBLIOTECAS COMO UM SISTEMA}

Livro e biblioteca têm suas histórias intrinsicamente relacionadas, afinal, as bibliotecas originalmente foram criadas para reunir, organizar e possibilitar o acesso a informações contidas em livros. Com o passar dos anos, outras fontes de informação registrada passaram a 
incorporar os acervos de bibliotecas, como periódicos, materiais audiovisuais, multimídias (CD-ROM, vídeos, mapas etc.), fontes digitais.

Seguindo-se a reflexão sobre sistemas, pode-se também identificar a biblioteca como um sistema. Esse sistema possui uma coleção de componentes, uma organização e uma estrutura com uma finalidade específica, que a diferencia, por exemplo, de uma livraria, que possui estrutura e organização semelhantes, porém, com fins diferenciados. Utilizando-se das palavras de Ranganathan (2009, p. 263), escritas em 1931: “[a biblioteca é] um instrumento de educação universal, que reúne e difunde livremente todos os recursos de ensino e dissemina o conhecimento [...]".

A literatura sobre gestão organizacional de bibliotecas universitárias, prioritariamente entende-as como um sistema aberto, tendo como justificativa básica as interações que fazem com o ambiente externo (OLIVEIRA, 2002). O macroambiente exerce sim uma influência sobre a organização, mas não se pode desconsiderar que o inverso igualmente acontece, ou seja, as bibliotecas também tem o poder de influenciar o seu meio. A esse processo perturbador e adaptativo entre sistema e meio foi denominado por Maturana (2001), de acoplamento estrutural, conforme conceito explicitado na seção anterior.

A relação metafórica da biblioteca como um organismo foi sugerida por Ranganathan. Professor de matemática e estudioso da Biblioteconomia, ele criou as cinco leis para as bibliotecas, sendo que a quinta e última lei diz que: a biblioteca é um organismo em crescimento. (RANGANATHAN, 2009), "Este último preceito, como os demais, conserva alto nível de atualização e adequação à dita sociedade da informação, sociedade do conhecimento ou sociedade da aprendizagem" (TARGINO, 2010, p. 123) e instiga a visualização de uma biblioteca viva e pulsante (RIZZI, 2016).

Ancorados nessa quinta lei de Ranganathan (2009) vislumbra-se a perspectiva de se analisar a biblioteca como um sistema orgânico. Relembrando que sistemas orgânicos, para Maturana e Varela (2001), são autopoiéticos, ou seja, têm a capacidade de se autorrenovarem.

Neste sentido, uma biblioteca ou um sistema de bibliotecas pode ser entendido como um sistema autopoiético, pois quem efetivamente implanta suas mudanças são as pessoas que compõem o sistema. A efetivação das transformações acontecem por meio de suas interações internas (indivíduo, grupo, organização), que processam as mudanças objetivando sua adaptação e conservação, sem perder sua organização-fim.

Entende-se, assim, que as bibliotecas estão em contínuo processo de aprendizado e renovação. Crossan, Lane e White (1999), expoentes na área de Aprendizagem Organizacional, afirmam que o processo de aprendizado ocorre em três níveis: individual, grupal e organizacional. O ponto de partida para um processo de renovação, mudança ou inovação é sempre o indivíduo, porém, os autores ressaltam que o desenvolvimento 
individual não garante o desenvolvimento da organização, a menos que existam condições para um aprendizado coletivo.

$\mathrm{Na}$ literatura internacional, a aplicação explícita do conceito de sistema e da sua aptidão para a biblioteconomia foram apresentadas por Kluth (1976 apud NAUMANN, 2007), como resultado de suas investigações, especialmente o valor prático que o conceito pode ter no trabalho com a mentalidade de sistemas no contexto da biblioteconomia:

[...] essencial parece-me pensar em sistemas, no todo, não em partículas ou parcelas. A questão de disciplina, particularismo, dualismo, a fragmentação, deve ser superada na biblioteconomia: ela deve ser vista como um todo, como um sistema de sistemas e subsistemas com os correspondentes para construir relações funcionais [...]. (KLUTH ${ }^{1}, 1976$ apud NAUMANN, 2007. Tradução nossa)

\subsection{Sistemas de bibliotecas em IES}

As bibliotecas acadêmicas brasileiras iniciam um período de expansão no final da década de 1960, impulsionadas pela reforma universitária, que criou diversas universidades a partir da junção de faculdades (NUNES, CARVALHO, 2016).

Paralelamente, nessa época, discussões sobre a importância da interação entre bibliotecas no contexto das Bibliotecas também começam a surgir. O professor Hamar (1967), ao refletir sobre o desenvolvimento das bibliotecas universitárias, ponderava que a organização destas se fazia de forma isolada e heterogênea, alheia a programas que tendessem para uma integração e criação de vínculos de colaboração. Hamar (1967), nesse período, já vislumbrava a importância da cooperação entre bibliotecas, porém, observava que a expansão das bibliotecas universitárias seguia ignorando as tendências voltadas para uma sistemática de integração.

Nas décadas de 1970 e 1980, a literatura sobre gestão de bibliotecas passa a fomentar a adoção da perspectiva sistêmica. Lima (1978) afirma que o planejamento da biblioteca deve ser sistêmico, considerando o ambiente do qual faz parte. Ferreira (1980) fundamenta sua pesquisa sobre os modelos de organização de bibliotecas universitárias com base em autores como Parsons, afirmando que "[...] toda a organização precisa ser estudada como um sistema, com todas as propriedades essenciais a qualquer sistema social, e também como subsistema de um sistema social maior" (PARSONS², 1980 apud FERREIRA, 1980, p.16).

\footnotetext{
${ }^{1}$ KLUTH, R. Theoretische Grundlagen der Bibliothekssysteme. In: Bibliothek und Buch in Geschichte und Gegenwart. Festgabe für Friedrich Adolf Schmidt-Künsemüller zum 65. Geburtstag am 30. Dez. 1975. München: Verlag Dokumentation, 1976. p. 161.

${ }^{2}$ PARSONS, T. Sugestões para um tratado sociológico da teoria da organização. In: ETZIONI, A. (Org) Organizações complexas. São Paulo: Atlas, 1967
} 
Ferreira (1980) esclarece que, ao darmos um enfoque sistêmico ao contexto das bibliotecas, deve-se considerar que ela é um dos subsistemas fundamentais das universidades e que não pode ser esquecida. Existe entre universidade e biblioteca um processo de retroalimentação: "À medida que a universidade busca melhores padrões de ensino e pesquisa, sente-se pressionada a dar melhores condições às bibliotecas para que funcionem com eficácia; e estas, por sua vez, funcionando adequadamente, dão melhor apoio aos programas educacionais da própria universidade. (FERREIRA, 1980, p. 9).

Corroborando esta mesma linha de pensamento, Tarapanoff (1982) explana detalhadamente a visão da biblioteca enquanto um sistema aberto e conclui que esse sistema está em constante interação com o seu meio ambiente (tanto externo quanto interno), porém, não tem autonomia própria e é dependente da universidade.

Na década de 80, outro marco importante que favoreceu a expansão das bibliotecas e a valorização das bibliotecas estruturadas em forma de sistema, seja por meio da adoção de modelos centralizados ou descentralizados, foi o desenvolvimento de cursos de pósgraduação.

Um Sistema de Bibliotecas, nessa época, era concebido como:

[...] um conjunto de bibliotecas que se dispuseram a obedecer um plano comum, visando determinado propósito ou objetivo, mantendo interação regular, interdependendo entre si para manutenção do sistema. Cada uma delas pode ter sua estrutura própria, propriedades e relações, mas, desde que se constituam em sistema, passam a interagir dentro de normas estabelecidas pelo plano comum, sob a coordenação de uma unidade aceita como cabeça do sistema. (MARTINS, 1980).

O conceito acima denota uma relação hierárquica entre as partes, com fortes traços de poder top-down quando utiliza os termos "obedecer" e "uma unidade aceita como cabeça do sistema”.

Cunha e Cavalcanti (2008) já apresentam uma conceituação mais generalista. Para os autores, um sistema de bibliotecas é um "[...] conjunto de bibliotecas, pertencentes ou não à mesma instituição e que estão interligadas por objetivos comuns”. Esse conceito é mais aberto, permitindo o seu uso no contexto de formação de sistemas em rede de bibliotecas, numa perspectiva interorganizacional.

Resgatando-se o conceito de Sistemas apresentado por Alves (2012), percebe-se sua aplicabilidade ao contexto de Sistemas de Bibliotecas, oferecendo as bases para sua reconceitualização. Sendo assim, sugere-se o seguinte conceito para um Sistema de Bibliotecas: "Sistema de Bibliotecas é uma organização composta por um conjunto de bibliotecas ou departamentos, inter-relacionados em uma dada estrutura, compondo uma unidade com objetivos comuns que o identificam como tal". 
Ao se pensar na visão sistêmica de Sistemas de Bibliotecas em instituições de ensino, é importante compreender que ele pertence a um supersistema e contempla, em sua estrutura interna, os subsistemas, conforme se visualiza na figura 1.

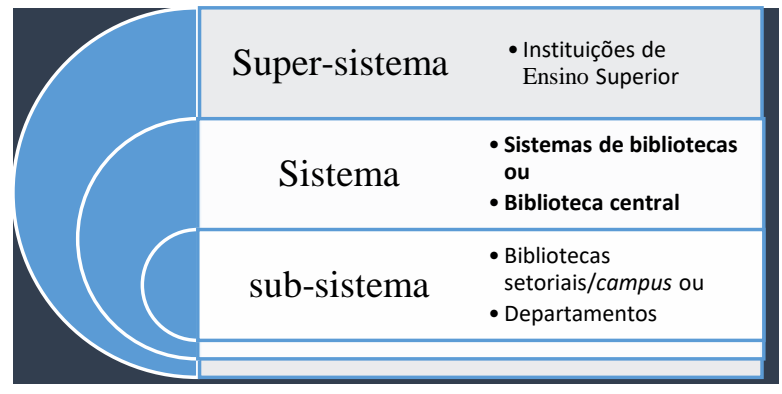

Figura 1 - Níveis de sistemas que envolvem as Bibliotecas

Fonte: Elaborado pelos autores com base em Tarapanoff (1982).

A literatura nacional a partir de 2000 também aborda discussões sobre "Sistemas de Bibliotecas" (CARVALHO; GOULART, 2004; PRADO; ABREU, 2006) e apresenta relatos sobre a implantação de Sistemas de Bibliotecas (CAMURÇA; ARAUJO; MORAES, 2013), porém, a visão sob o ponto de vista de organização aberta permanece enfática.

Na última década, começam a aparecer, na literatura nacional, estudos na área fundamentados em outros autores, como o de Carvalho (2012), que utiliza a teoria de Luhmann (1998), construída com base na visão autopoiética. Os estudos sobre gestão de bibliotecas de IES que abordam o tema de gestão do conhecimento também passam a reconhecer a Biblioteca Universitária (BU) como um sistema complexo. Nessa linha de pensamento pode-se citar o trabalho de Bem (2015), em que a autora, em seu doutoramento, apresenta a proposta de um framework para Gestão do Conhecimento a partir do entendimento da BU como um "Sistema Adaptativo Complexo". Outro trabalho é o de Sales (2015), que propõe o gerenciamento do sistema de bibliotecas de um instituto federal da RFEPCT à luz do "Modelo de Sistema Viável” concebido por Beer (1979).

\subsection{Estrutura organizacional de Sistema de Bibliotecas}

Os resultados da pesquisa conduzida por Ferreira (1980), que tinha como propósito investigar o grau de centralização e descentralização das bibliotecas universitárias, apontou que havia uma tendência para a centralização, podendo esta ser parcial (apenas os serviços de aquisição e/ou processamento técnico) ou total e monolítica, neste caso caracterizando a ausência de bibliotecas seccionais. A autora enfatiza que, independente do grau de interação entre as bibliotecas, é fundamental que estas se organizem em forma de sistemas, a fim de possibilitarem melhores condições de trabalho, maiores recursos e viabilizarem os processos de automação. 
A figura 2 descreve os seis níveis identificados por Ferreira (1980), de estruturas organizacionais de Sistemas de Bibliotecas (SIBIs), desde a categoria de centralização máxima, denominada de "Centralização monolítica", até o nível de descentralização coordenada.

O sétimo e último nível apresentado representa a ausência de qualquer tipo de organização que estabeleça conexão entre um grupo de bibliotecas de uma instituição, não podendo ser conceituado como um SIBI. Na visão da autora, os níveis de centralização parcial se enquadram em uma perspectiva mais equilibrada, pois a autora considera que o excesso de centralização dificulta o processo de gestão.

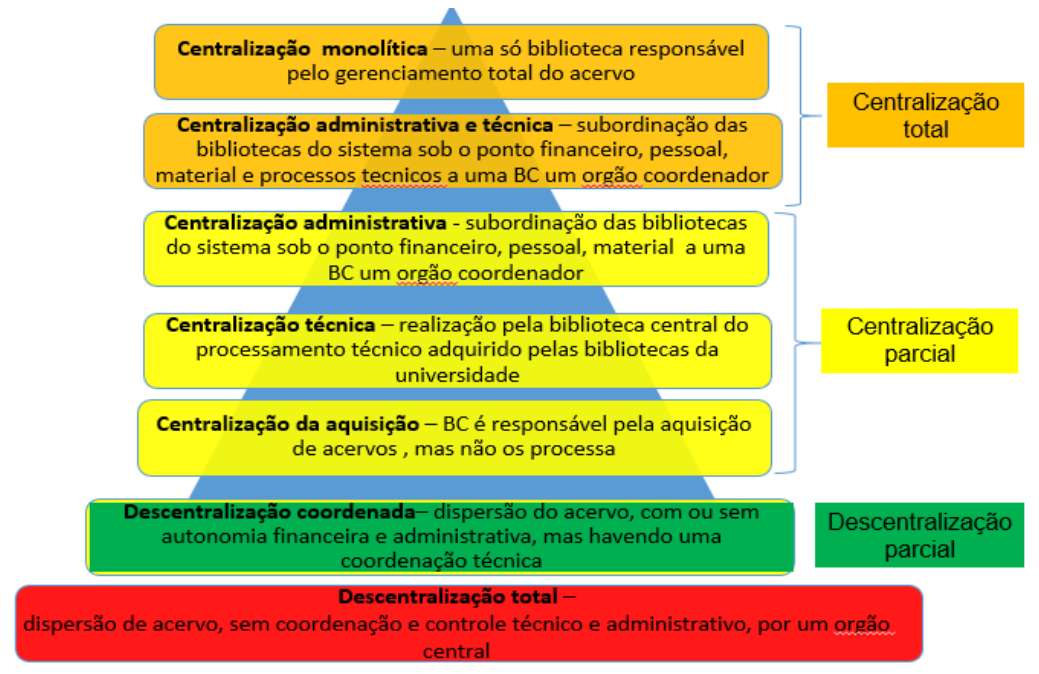

Figura 2 - Níveis de centralização/descentralização em Sistemas de Bibliotecas

Fonte: elaborado pelos autores com base em Ferreira (1980).

Passados dez anos, Mercadante (1990) investiga sobre o mesmo tema, identificando, na maioria das 78 Bibliotecas Universitárias pesquisadas, a presença de modelos organizacionais com coordenação sistematizada e regulamentação oficial. Esse trabalho se posiciona de forma clara e enfática quanto à necessidade de que todas as BUs se integrem e se estruturem, tendo uma coordenação unificada.

Após 15 anos, Prado e Abreu (2005) apresentam os resultados de uma pesquisa envolvendo o tema sobre estruturas organizacionais de BUs do Estado de Santa Catarina. Os resultados apontaram que a maioria das instituições pesquisadas possui estruturas organizacionais vinculadas à alta administração, como órgão suplementar desta. Nas estruturas envolvendo bibliotecas setoriais, os autoras constataram predominância de subordinação administrativa e técnica. Estudos de Almeida (2013) e Silva (2015), realizados em nível nacional, ratificam esses resultados.

Níveis de centralização ou descentralização em estruturas organizacionais de Sistemas de Bibliotecas remetem a outra discussão, referente aos níveis de verticalidade ou

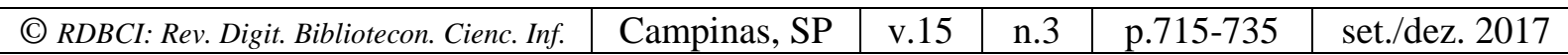


horizontalidade na sua estrutura organizacional. Andrade et al. (1998) apresentam uma proposta de estrutura mais horizontalizada (figura 3) justificando que:

A estrutura hierárquica verticalizada não favorece o fluxo da informação com a qualidade e agilidade necessárias às novas tendências, uma vez que a comunicação se faz de cima para baixo. Já a estrutura horizontal permite melhor compartilhamento de responsabilidades, a partir de uma comunicação em rede, facilitando o seu fluxo e atingindo com mais eficiência a clientela.

Aqui os autores citaram um ponto estratégico na discussão: estruturas mais horizontais facilitam o compartilhamento de responsabilidades. O organograma apresentado na figura 3 permite visualizar a nova proposta criada para uma biblioteca composta de vários departamentos. As interações entre os diversos departamentos ocorrem por meio do desenvolvimento de projetos e programas.

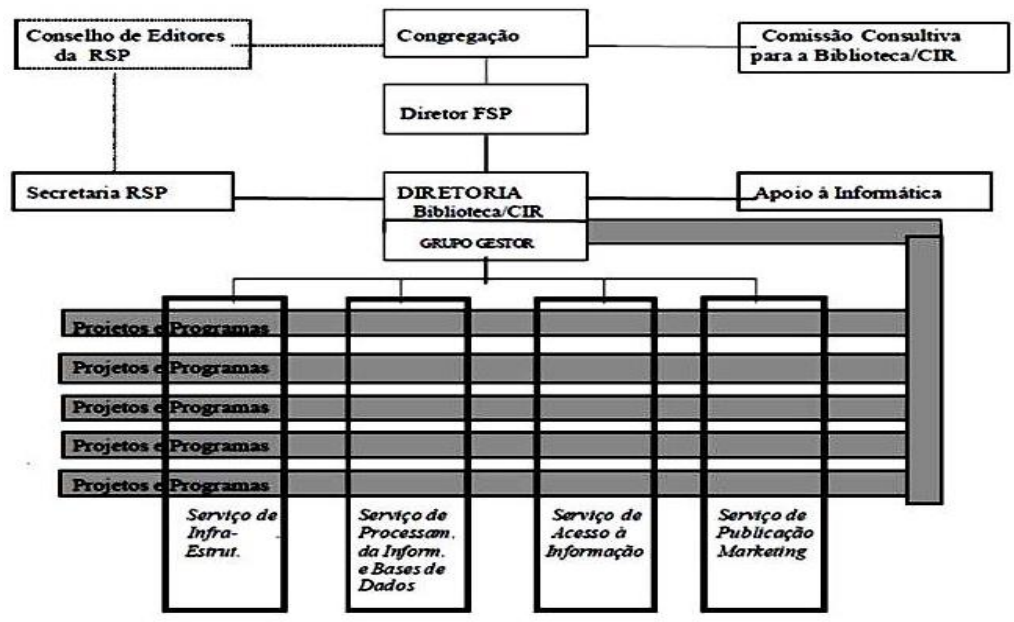

Figura 3 - Organograma da biblioteca/CIR - 1997

Fonte: Andrade et al. (1998).

Sobre a visão sistêmica do modelo, Andrade et al. (1998) apresentam as premissas básicas que o fundamentam:

- considerar as ações das áreas como partes de um todo, percebendo a organização como um sistema;

- criar condições de flexibilidade e abrangência, para poder atuar no sistema de forma global e respeitando os subsistemas de dimensões distintas e seus diferentes graus de eficiência, eficácia e desenvolvimento;

- utilizar uma tecnologia compatível com o estágio de desenvolvimento da biblioteca, observando as dimensões sociais e técnico-administrativas.

Observa-se, assim, que as estruturas de Sistemas de Bibliotecas de IES brasileiras adotam modelos que variam entre alta centralização de poder (administrativo e técnico) e centralização parcial (administrativo ou técnico), podendo organizar-se em estruturas hierárquicas verticalizadas ou mais horizontalizadas. Também foi observado, pelos estudos, que existe uma preocupação com os níveis participativos nos processos decisórios, 
apontando-se que as estruturas mais horizontais oportunizam maior descentralização do poder e maior autonomia aos departamentos ou setoriais.

\section{PROCEDIMENTOS METOdOLÓgICOS}

Este trabalho caracteriza-se como uma pesquisa descritiva de cunho qualitativo, utilizando-se como técnica a pesquisa documental.

A pesquisa documental analisa documentos, sendo semelhante à pesquisa bibliográfica, com a ressalva para a diferença das fontes de informação usadas. Segundo Gil $(2008,51)$, este tipo de pesquisa utiliza-se de “[...] materiais que não receberam ainda um tratamento analítico, ou que ainda podem ser reelaborados de acordo com os objetivos da pesquisa", como: planejamentos, relatórios de gestão, regimentos, regulamentos e informações disponibilizadas em sites.

Durante o mês de abril de 2016, realizou-se uma pesquisa em sites de "Sistemas de Bibliotecas" de universidades federais, universidades estaduais e instituições da Rede Federal de Educação profissional. Na pesquisa, constatou-se que um número reduzido de instituições disponibiliza o acesso público a seus regimentos. Dentre os regimentos localizados, foram selecionados 15 para análise, utilizando os seguintes critérios:

a) 33\% de regimentos com data de aprovação anterior a 2000 (quatro, de SIBIs de universidades federais e um, de universidade estadual);

b) 33\% com aprovação entre 2001 e 2010 (quatro, de SIBIs de universidades federais e um, de universidade estadual); e

c) 33\% com aprovação entre 2011 e 2016 (três, de SIBIs da RFEPCT; um, de universidade federal e um, de universidade estadual).

A escolha do conjunto de regimentos referente a cada critério deu-se aleatoriamente, conforme a disponibilidade de acesso.

Na sequência fez-se a leitura dos regimentos e a seleção dos trechos que continham informações relacionadas aos seguintes temas de análise:

a) estrutura organizacional do sistema;

b) forma de vinculação com o supersistema;

c) forma de organização de subsistemas.

Os resultados e análises são apresentados na próxima seção, organizados em subseções por categoria.

\begin{tabular}{l|l|} 
v.15 & n. 3
\end{tabular}




\section{RESULTADOS E DISCUSSÕES}

Nesta seção, apresenta-se a análise dos regimentos dos 15 Sistemas de Bibliotecas de IES selecionados, a fim de atender ao objetivo proposto na pesquisa.

\subsection{Quanto à estrutura organizacional dos SIBIs}

Constatou-se que as estruturas organizacionais de SIBIs de universidades, de forma geral, possuem uma configuração hierárquica, tendo como órgão superior um conselho ou colegiado, composto de representantes da estrutura do supersistema, podendo ser deliberativo, deliberativo e consultivo ou só consultivo. Nos regimentos de SIBIs da RFEPCT, constatou-se estrutura semelhante, porém o conselho superior tende a ser composto somente por membros internos do Sistema.

No segundo nível (ou terceiro nível, conforme o caso), aparece o órgão coordenador do SIBI, que, em algumas instituições, está acoplado a uma biblioteca central, e em outras, ele pertence a uma estrutura independente.

E em terceiro plano (ou quarto nível, conforme o caso), aparecem as bibliotecas de campus ou bibliotecas setoriais (subsistemas). O regimento de um SIBI descreve a existência de comissões com funções de conselho ou colegiado em cada campus. Sendo assim, cada biblioteca de campus (setorial) possui um órgão deliberativo, composto por pessoas externas ao subsistema em questão.

Outro diferencial encontrado em dois regimentos é a menção de comissões temáticas internas, que objetivam desenvolver estudos e trabalhos. Essas comissões podem ser compostas por membros externos à biblioteca, quando se fizer necessário.

A figura 4 ilustra os níveis encontrados, porém, deve-se esclarecer que nenhum dos regimentos possui esta configuração completa. 


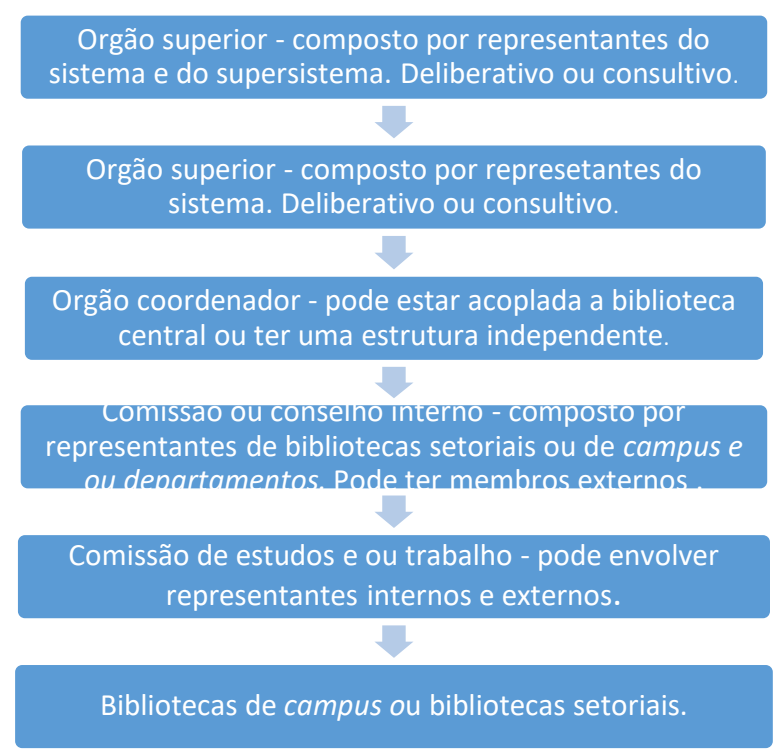

Figura 4 - Níveis hierárquicos encontrados nas estruturas organizacionais de SIBIs

Fonte: Elaborado pelos autores (2017).

Observou-se, também, que 13 dos 15 regimentos analisados têm, nos seus sistemas de bibliotecas, um órgão colegiado, que atua na esfera consultiva e/ou deliberativa, cabendo a ele, entre outras atribuições, apreciar e aprovar o planejamento anual, a proposta orçamentária e as políticas e regulamentações propostas pelo Sistema. Seis regimentos de SIBIs de universidades informam a existência de um subsistema administrativo e financeiro.

Comissões e grupos de trabalho são contemplados apenas em três regimentos. Dois SIBIs mencionam em seu regimento a existência de Núcleos de Pesquisa e Extensão. O regimento de um deles descreve que o papel do núcleo é oferecer cursos de qualificação, treinamento e aperfeiçoamento voltados para as equipes das bibliotecas e comunidade externa.

Nos regimentos analisados, pôde-se perceber que alguns Sistemas buscam garantir maior participação nos níveis decisórios, envolvendo representantes do supersistema e do subsistema, porém, este posicionamento não está presente na maioria.

\subsection{Quanto à relação dos Sistemas de Bibliotecas com o supersistema}

Os sistemas de bibliotecas de universidades analisados, tanto federais como estaduais, são considerados pelo supersistema, na sua maioria, como órgãos suplementares e vinculamse administrativamente à respectiva reitoria ou vice-reitoria, independente da época em que foram aprovados. Apenas um dos sistemas pertencente a universidade é vinculado a uma próreitoria. 
O destaque diferencial, neste caso, relaciona-se aos sistemas de bibliotecas da RFEPCT, cuja vinculação administrativa descrita nos três regimentos dá-se junto à PróReitoria de Ensino. Considerando que as bibliotecas têm por finalidade atender às ações de ensino, pesquisa, extensão e inovação, causa estranheza essa posição de subordinação à PróReitoria de Ensino, posto que tal posicionamento limita as inter-relações com as outras próreitorias.

\subsection{Quanto aos níveis de autonomia decisória dos SIBIs}

Um dos primeiros pontos avaliados nos regimentos em relação à questão de autonomia refere-se à escolha dos dirigentes do sistema, assim como dos subsistemas. Nesse sentido, constata-se que a maioria dos regimentos que abordam este quesito informa que o processo de escolha é do reitor. Dentro de estruturas burocráticas em que se enquadra a grande maioria das instituições de ensino, este era um resultado esperado. A diferença encontrada entre os regimentos é que alguns definem que os conselhos de bibliotecas homologam uma lista tríplice, com a indicação de candidatos à coordenação ou direção geral dos SIBIs.

\subsection{Quanto aos níveis de centralização/descentralização dos SIBIs}

A discussão quanto aos níveis de centralização de Sistemas de Bibliotecas, conforme pode ser visto na revisão, é tema recorrente e não existe consenso sobre qual seria o mais adequado. No momento de criação/atualização de um SIBI, a configuração da estrutura organizacional desejada é comumente proposta por uma equipe de bibliotecários que nele trabalham, mas, como estão subordinados a uma unidade maior, dependem de aprovação do supersistema ao qual pertencem. Muitas vezes o que é considerado ideal para um Sistema de Bibliotecas não é o que efetivamente se consolida.

Sistemas de Bibliotecas de universidades tendem a ter estruturas mais rígidas quanto à subordinação das bibliotecas setoriais, havendo maior centralização quanto aos processos de orçamento, aquisição, catalogação e de pessoal (bibliotecários).

Sistemas de Bibliotecas da RFEPCT se organizam dentro de um modelo com maior descentralização, refletindo a estrutura organizacional das instituições a que pertencem. A maioria dos processos referente a orçamento, aquisição e execução dos procedimentos técnicos são da competência de cada biblioteca. A coordenação do sistema é a responsável pelo funcionamento integrado das mesmas, com a padronização da gestão, dos procedimentos técnicos internos e dos serviços.

De forma geral, nos regimentos aprovados entre 2011 a 2016, percebeu-se que as estruturas internas dos SIBIs tendem a ter um nível mais baixo de centralização, primando especialmente pela padronização técnica e integração do sistema. A operacionalização dos 
processos técnicos e da aquisição tendem a ser descentralizada. Neste caso, nota-se inclusive uma mudança de nomenclatura: de bibliotecas setoriais para bibliotecas de campus.

Outro ponto a destacar, na análise dos relacionamentos entre órgão coordenador do SIBI e as bibliotecas de campus ou setoriais, é o seu nível de subordinação e participação decisória junto ao SIBI, em que foram identificadas as seguintes situações:

a) subordinação administrativa e técnica, com poder de decisão por meio da participação no conselho superior deliberativo do Sistema ou órgão similar;

b) subordinação técnica, com poder de decisão por meio da participação no conselho superior deliberativo do Sistema ou órgão similar;

c) subordinação administrativa e técnica, sem poder de decisão (ausência de conselho deliberativo ou órgão similar);

d) subordinação técnica, sem poder de decisão (ausência de conselho deliberativo ou órgão similar).

Observou-se também que existe a tendência, nos regimentos datados de 2011 a 2016, de terem instâncias que incluam os responsáveis de bibliotecas de campus ou setoriais nas tomadas de decisão do SIBI.

\section{CONSIDERAÇÕES FINAIS}

A relevância da organização das bibliotecas de IES dentro de uma perspectiva sistêmica é um consenso na literatura nacional. Ao longo da história nos últimos 40 anos, constatou-se que existem algumas modificações nas suas concepções. No início, a visão sistêmica de bibliotecas ancorava-se nos princípios teóricos de Bertalanffy (c1969), entendendo-as como um sistema aberto.

Estudos nas últimas décadas sobre sistemas ampliam esta visão, passando a visualizálos como sistemas autopoiéticos (MATURANA; VARELA 2001; LUHMANN, 1998) e complexos (MORIN, 2006), ou seja, estruturas complexas com capacidade de se autoorganizarem. A revisão da literatura nacional parece indicar uma tendência, ainda que tênue, de os estudos organizacionais de sistemas de bibliotecas incorporarem esta nova visão.

Constatou-se também que o conceito de Sistema de Bibliotecas apresentado na literatura brasileira, dirigido ao contexto de uma instituição, carecia de atualização. Com base no conceito de Sistema de Alves (2012), sugere-se a seguinte definição: "Sistema de Bibliotecas é uma organização composta por um conjunto de bibliotecas ou departamentos inter-relacionados em uma dada estrutura, compondo uma unidade com objetivos comuns, que o identificam como tal."

A estrutura de Sistemas de Bibliotecas pode ser organizada dentro de modelos com níveis variados de centralização/descentralização de poder, serviços e produtos. A análise dos

\begin{tabular}{l|l|l}
$\mathrm{v} .15$ & $\mathrm{n} .3$ \\
\hline
\end{tabular}

p.715-735
set./dez. 2017 
regimentos de SIBIs de universidades e de instituições da RFEPCT denota que os sistemas possuem uma estrutura organizacional verticalizada, dentro dos padrões burocráticos normais deste tipo de instituição de ensino. O que foi possível perceber, nos regimentos da década atual, é uma leve tendência para a composição de estruturas menos centralizadas e com maior nível de participação dos gestores de bibliotecas de campus nas decisões tomadas pelo SIBI. Outro ponto marcante é a descentralização da execução dos procedimentos técnicos dos recursos bibliográficos, porém, primando pela padronização dos mesmos.

Quanto à vinculação dos SIBIs com o supersistema (instituição a que pertencem), constata-se uma diferença significativa entre os SIBIs de universidades e de instituições da RFEPCT. Nas universidades, os vínculos tendem a se manter conectados diretamente aos níveis da alta administração, como órgãos suplementares, em sua maioria. Já o mesmo não acontece com os SIBIs da RFEPCT, os quais estão vinculados aos níveis de pró-reitoria. Sendo assim, considera-se relevante o aprofundamento de pesquisas na área visando identificar possíveis causas e impactos referente ao nível vinculação administrativa sobre a gestão de Sistemas de Bibliotecas e consequente desempenho institucional.

As maiores mudanças passíveis de identificação por meio dos regimentos foram percebidas nos níveis de relação do SIBI (sistema) e de seus subsistemas, ou seja, inovações geradas internamente, dentro de um movimento de auto-organização e autorrenovação. Esta é uma capacidade descrita por Maturana e Varela (2001) para sistemas autopoiéticos e também entendida como uma característica de sistemas complexos, apresentada por Morin (2006).

A análise dos cinco regimentos publicados entre 2011 e 2016 permite também inferir que pode estar ocorrendo uma modificação na concepção de estruturas de SIBIs, saindo de modelos estruturais mais centralizados para estruturas com menor centralização de serviços internos, porém mantendo uma centralização da gestão, com padronização de processos e serviços, e ampliando a participação dos representantes de campus nas esferas decisórias.

Ressalta-se que esta pesquisa teve uma perspectiva descritiva e qualitativa, com base em 15 regimentos, e, portanto, seus resultados não podem ser generalizados. Considera-se relevante que novos estudos sobre o tema sejam realizados buscando compreender de forma mais abrangente os movimentos de inovação em estruturas organizacionais de SIBIs.

\section{REFERÊNCIAS}

ALMEIDA, V. M. S. de. Os órgãos coordenadores e a gestão de sistemas de bibliotecas universitárias das instituições federais de ensino superior. 2013. 217 f. Dissertação (Mestrado Profissional em Administração) - Programa de Mestrado Profissional em Administração, Faculdade de Estudos Administrativos de Minas Gerais, Belo Horizonte, 2013.

ALVES, J. B. da M. Teoria Geral de Sistemas. Florianópolis: Instituto Stela, 2012. 
ANDRADE, M. T. D. de et al. Mudanças e inovações: novo modelo de organização e gestão de biblioteca universitária. Ci. Inf., Brasília, v. 27, n. 3, set./dez. 1998.

BECKER, C. da R. F.; FAQUETI, M. F. Panorama das bibliotecas da Rede Federal de Educação Profissional, Científica e Tecnológica: um olhar sobre a gestão. Blumenau, Instituto Federal Catarinense, 2016.

BEER, S. Cibernética na administração: visão totalmente original de como organizar e administrar desde uma pequena empresa até um país. São Paulo: IBRASA, 1979.

BEM, R. M. de. Framework de Gestão do Conhecimento para bibliotecas universitárias. 2015. 344p. Tese (Doutorado em Engenharia e Gestão do Conhecimento) - Programa de Pós-Graduação em Engenharia e Gestão do Conhecimento, Universidade Federal de Santa Catarina, Florianópolis, 2015.

BERTALANFFY, L. von. Teoria General de los Sistemas. México: FCE, c1969.

BRASIL. Presidência da República. Lei no 5.540, de 28 de novembro de 1968. Fixa normas de organização e funcionamento do ensino superior e sua articulação com a escola média. Diário Oficial da União, Brasília, 29 nov. 1968.

CAMURÇA, T. A.; ARAÚJO, I. F.; MORAIS, S. M. P. de. A construção de um sistema integrado de bibliotecas no Instituto Federal do Ceará: motivação, dificuldade e expectativas. In: CONGRESSO BRASILEIRO DE BIBLIOTECONOMIA, DOCUMENTAÇÃO E CIÊNCIA DA INFORMAÇÃO, 25., 2013, Florianópolis. Anais eletrônicos... Disponível em: < http://portal.febab.org.br/anais/article/view/1464 >1. Acesso em: 15 mar. 2014.

CARVALHO, C.; GOULART, S. Transformações de modelos organizacionais e poder nas bibliotecas universitárias brasileiras: o impacto da sociedade da informação. In: CONGRESSO LUSOBRASILEIRO DE CIÊNCIAS SOCIAIS, 8., 2004, Coimbra. Anais... Coimbra: Centro de Estudos Sociais, 2004. 10p.

CARVALHO, L. Informação e comunicação na administração das bibliotecas universitárias: entre as metáforas de Morgan e a visão de Luhmann. 2012. In: SEMINÁRIO NACIONAL DE BIBLIOTECAS UNIVERSITÁRIAS 2012. Anais... Gramado, RS, UFRGS, 2012.

CROSSAN, M. M.; LANE, H.W.; WHITE, R. E. An organizational learning framework: from intuition to institution. Academy of Management Review, v. 24, n. 3, p. 522-537, 1999.

CUNHA, M. B. da; CAVALCANTI, C. R. de O. Dicionário de Biblioteconomia e Arquivologia. Brasília: Briquet de Lemos Livros, 2008.

FERREIRA, L. S. Bibliotecas universitárias brasileiras: análise de estruturas centralizadas e descentralizadas. São Paulo: Pioneira, 1980.

GIL. Métodos e técnicas de pesquisa social. 6. ed. São Paulo: Atlas, 2008.

HAMAR, A. A. Bibliotecas universitárias: análise da situação brasileira e sugestões. Trabalho apresentado ao $5^{\circ}$ CONGRESSO BRASILEIRO DE BIBLIOTECONOMIA E DOCUMENTAÇÃO, Anais... São Paulo, 1967. 11p.

HOUAISS, A.; VILLAR, M. de S.; FRANCO, F. M. de M. (Eds.). Dicionário Houaiss da Língua Portuguesa. Rio de Janeiro: Objetiva, 2009, p. 1190.

\begin{tabular}{l|l|} 
v.15 & n.3
\end{tabular}

p.715-735
set./dez. 2017 
LIMA, E. A biblioteca no ensino superior. Brasília: CAPES/ABDF, 1978.

LUHMANN, N. Complejidad y modernidade: de la unidad a la diferencia. Madrid: Trotta, 1998. $257 \mathrm{p}$.

MARTINS, M. G. de. Planejamento bibliotecário. São Paulo: Pioneira; Brasília, DF: INL, 1980. 166p. (Manuais de estudo)

MATURANA, R. H. Cognição, ciência e vida cotidiana. Belo Horizonte: UFMG, 2001.

MATURANA, R. H.; VARELA, F. J. A árvore do conhecimento: as bases biológicas do entendimento humano. 9. ed. São Paulo: Palas Athena, 2001.

MERCADANTE, L. M. Z. Análise de modelos organizacionais de bibliotecas universitárias nacionais. Brasília: PNBU, 1990.

MORIN, E. Introdução ao pensamento complexo. Porto Alegre: Sulina, 2006.

NAUMANN, U. Hochschul bibliotheks system eimVergleich. Universitätzu Berlin Sommersemester, 2007.

NUNES, M. S. C.; CARVALHO, K. As bibliotecas universitárias em perspectiva histórica: a caminho do desenvolvimento durável. Perspectivas em Ciência da Informação, v.21, n.1, p.173-193, jan./mar 2016.

OLIVEIRA, S. M. de. Gerenciamento organizacional de bibliotecas universitárias. In: SEMINÁRIO NACIONAL DE BIBLIOTECA UNIVERSITÁRIA, 12, 2002. Anais.... Recife, 2002.

PRADO, N. S.; ABREU, J. de. Modelos de organização e gestão das bibliotecas universitárias do estado de Santa Catarina. Revista ACB, Florianópolis, v. 10, n. 1, p. 107-123, 2005.

RANGANATHAN, S. R. As cinco leis da Biblioteconomia. Brasília: Briquet de Lemos Livros, 2009.

RIZZI, I. R. F. As cinco leis da biblioteconomia no Brasil. In: LUCAS, E. R. de O.; CORRÊA, E. C. D.; EGGERT-STEINDEL, G. (Orgs.). As contribuições de Ranganathan para a Bibilioteconomia: reflexões e desafios. São Paulo: FEBAB, 2016. 222 p.

SALES, K. B. Modelo de sistema de gestão viável para bibliotecas do IFAM. 2015. 217f. Dissertação (Mestrado profissional em Gestão de Unidades de Informação) - Programa de Pós-Graduação em Gestão da Informação, Universidade do Estado de Santa Catarina, 2015.

SILVA, A. B. da. Gestão de sistemas de bibliotecas no desenvolvimento de serviços nas universidades federais brasileiras. 2015. 268 f. Dissertação (Mestrado em Ciência da Informação) Programa de Pós-Graduação em Ciência da Informação, Universidade Federal da Bahia, 2015.

TARAPANOFF, K. A biblioteca universitária vista como uma organização social. Estudos avançados em Biblioteconomia e Ciência da Informação. Brasília: ABDF, v. 1, p. 73-92, 1982.

TARGINO, M. das G. Ranganathan continua em cena. Ci. Inf., Brasília, v. 39, n. 1, p. 122-124, Apr. 2010.

\begin{tabular}{|c|c|c|c|c|c|}
\hline (C) & Campinas, SP & v.15 & n.3 & p.715-735 & \\
\hline
\end{tabular}



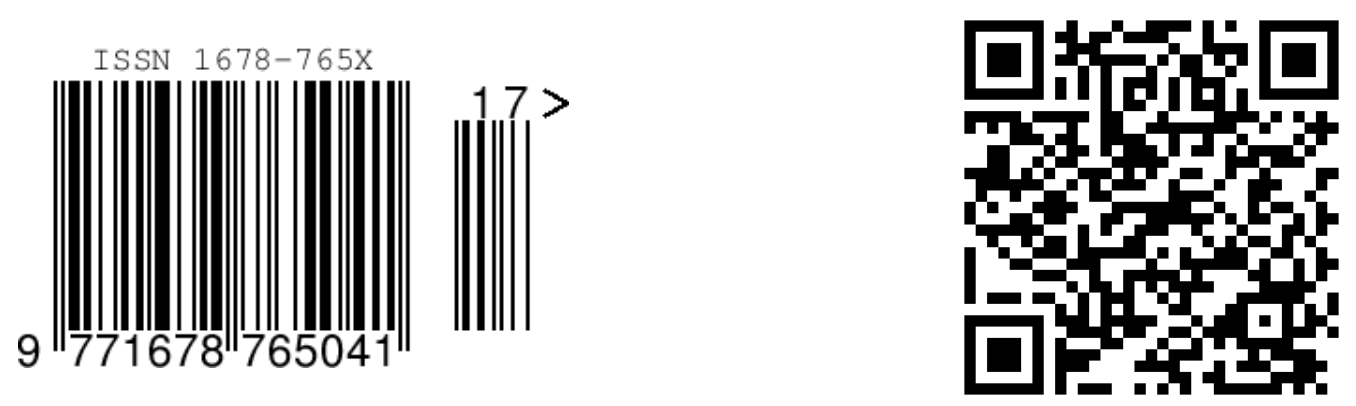